\title{
Serum cytokine and adhesion molecule profile differs in newly diagnosed acute myeloid and lymphoblastic leukemia
}

\author{
Jan M. Horacek ${ }^{\mathrm{a}, \mathrm{b}}$, Tomas Kupsa ${ }^{\mathrm{a}, \mathrm{b}}$, Martina Vasatovac, Ladislav Jebavy ${ }^{\mathrm{a}, \mathrm{b}}$, Pavel Zak ${ }^{\mathrm{b}}$
}

\begin{abstract}
Aims. To compare serum levels of 17 cytokines and 5 adhesion molecules in patients with newly diagnosed acute myeloid leukemia (AML) and acute lymphoblastic leukemia (ALL) using biochip array technology.

Methods. A total of $15 \mathrm{AML}$ and $15 \mathrm{ALL}$ patients were studied. Serum samples were taken prior to anticancer therapy and were analyzed by biochip based immunoassays on the Evidence Investigator analyzer. This approach allows simultaneous detection of multiple analytes from a single sample. T-tests were used for statistical analysis.

Results. Comparing cytokine and adhesion molecules levels in newly diagnosed AML and ALL patients, we found significant increase in AML in serum IL-4 $(P<0.0001)$, IL-2 $(P<0.01)$, IL-3 $(P<0.05)$, and significant decrease $(P<0.05)$ in serum VEGF and VCAM-1.

Discussion. Our results indicate that serum profile of cytokines and adhesion molecules differs in newly diagnosed AML and ALL patients. Further studies are needed to establish if these alterations could be used as a clinically relevant biomarker for acute leukemias.
\end{abstract}

Key words: cytokines, adhesion molecules, biochip array, acute leukemia

Received: April 15, 2014; Accepted with revision: September 23, 2014; Available online: October, 29, 2014 http://dx.doi.org/10.5507/bp.2014.051

a Department of Internal Medicine, University of Defence, Faculty of Military Health Sciences, Hradec Kralove, Czech Republic ${ }^{b} 4^{\text {th }}$ Department of Internal Medicine - Hematology, Faculty of Medicine in Hradec Kralove, Charles University in Prague and University Hospital Hradec Kralove

Institute of Clinical Biochemistry and Diagnostics, University Hospital Hradec Kralove

Corresponding author: Pavel Zak, e-mail: pavel.zak@fnhk.cz

\section{INTRODUCTION}

Cytokines and adhesion molecules have been studied in many pathological states including cancer $^{1-3}$ and acute leukemias, both myeloid (AML) and lymphoblastic (ALL) (ref. $\left.{ }^{4-6}\right)$. Alterations in this interacting functional network may have direct effect on the malignant cells or have indirect effect on leukemogenesis through altered functions of bone marrow stromal elements ${ }^{7-9}$. The knowledge gained from multi-analytical determination of cytokines and adhesion molecules could allow better diagnosis and management of hematological malignancies, since cytokines or their receptors may also represent a target for specific anticancer therapy at the molecular level. Recently, some studies reported the possible diagnostic and prognostic use of cytokine levels in newly diagnosed acute leukemias and myelodysplastic syndromes ${ }^{10-14}$.

The aim of our pilot study was to evaluate serum profile of multiple cytokines and adhesion molecules in patients with newly diagnosed AML and ALL using the innovative biochip array technology. This generates a patient profile, which is relevant when investigating interacting functional networks.

\section{PATIENTS AND METHODS}

\section{Subjects}

A total of 15 newly diagnosed AML patients (median age 51, range 24-61 years, 8 males and 7 females) and 15 newly diagnosed ALL patients (median age 46, range 24-63 years, 11 males and 4 females) were studied. None of the patients had a history of cancer or autoimmune disease. The study was approved by the local Ethics Committee and all patients gave a written consent.

Multi-analytical evaluation using biochip array technology

We evaluated serum levels of the following 17 cytokines and 5 adhesion molecules: interleukins (IL-1 alpha, IL-1 beta, IL-2, IL-3, IL-4, IL-6, IL-7, IL-8, IL-10, IL12p70, IL-13, IL-23), vascular endothelial growth factor (VEGF), tumor necrosis factor-alpha (TNF-alpha), interferon-gamma (IFN-gamma), epidermal growth factor (EGF), monocyte chemotactic protein-1 (MCP-1), E-selectin, L-selectin, P-selectin, intercellular adhesion molecule-1 (ICAM-1), vascular cell adhesion molecule-1 (VCAM-1). All analytes were measured by biochip array technology on Evidence Investigator analyzer (Randox Laboratories Ltd., Crumlin, UK).

Biochip array technology enables simultaneous quantitative detection of multiple analytes (e.g. cytokines and adhesion molecules) in a single patient sample and provides valuable information relating to each tested ana- 
lyte and possible associations between analytes in each sample ${ }^{15,16}$. The core technology is the biochip, a solidstate device containing an array of discrete test regions of immobilised antibodies specific to different cytokines and adhesion molecules. A sandwich chemiluminescent immunoassay is employed for the array. Increased levels of cytokine or adhesion molecule in a specimen will lead to increased binding of antibody labelled with horseradish peroxidase and thus an increase in the chemiluminescent signal emitted. The light signal generated from each of the test regions on the biochip is detected using digital imaging technology and compared to that from a stored calibration curve. The concentration of analyte present in the sample is calculated from the calibration curve ${ }^{17,18}$.

\section{Statistical analysis}

Statistical analysis was performed with the "Statistica" program. T-tests were used. The values were expressed as mean \pm SD. Probability values $(P)<0.05$ were considered statistically significant.

\section{RESULTS}

Comparing cytokine and adhesion molecules levels in newly diagnosed AML and ALL patients, we found significant increase in AML in serum IL-4 (4.71 \pm 2.69 ng/L vs. $1.10 \pm 1.08 \mathrm{ng} / \mathrm{L} ; P<0.0001)$, IL-2 (10.69 \pm 8.55 ng/L vs. $4.03 \pm 2.15 \mathrm{ng} / \mathrm{L} ; P<0.01), \mathrm{IL}-3$ (18.84 \pm 21.63 ng/L vs. $7.34 \pm 3.41 \mathrm{ng} / \mathrm{L} ; P<0.05)$, and significant decrease in serum VEGF $(63.93 \pm 67.85 \mathrm{ng} / \mathrm{L}$ vs. $139.33 \pm$ $133.47 \mathrm{ng} / \mathrm{L} ; P<0.05)$, VCAM-1 (716.22 $\pm 364.38 \mathrm{mcg} / \mathrm{L}$ vs. $1078.54 \pm 456.96 \mathrm{mcg} / \mathrm{L} ; P<0.05)$. No significant differences were found in the levels of other evaluated cytokines and adhesion molecules.

Levels of cytokines and adhesion molecules with significant differences are clearly shown in Table 1 .

\section{DISCUSSION}

Cytokines comprise a rather numerous group of substances, in particular of glycoprotein or protein nature, functioning as local hormones. In a paracrine or autocrine manner, they influence the direction, intensity and duration of immune and inflammatory responses as well as other physiological and pathophysiological manifesta- tions of cells. Cytokines are interconnected in a network that is responsible for information exchange within the immune system as well as for information interchange between the immune system and other systems of the body. Cytokines include interleukins, tumor necrosis factors, interferons, colony stimulating factors, transforming growth factors, chemokines (intercrines) and others.

Adhesion molecules are glycoproteins or lectins which participate in interactions among immune system cells, in particular during the colonization of primary and secondary lymphoid organs, and in inflammatory responses. They belong to several families such as selectins, members of the immunoglobulin superfamily (e.g. ICAM-1, VCAM-1), integrins and cadherins.

Altered levels of cytokines and adhesion molecules have been found in many pathological states and have been linked to many diseases such as autoimmune diseases, allergies, cardiovascular diseases and cancer ${ }^{19-24}$. The cytokine system constitutes an interacting functional network where the contribution from single cytokines is modulated by the levels of other cytokines. It may therefore be more relevant to look at the total serum profile of cytokines and adhesion molecules.

Our results indicate that serum profile of cytokines and adhesion molecules differs in newly diagnosed AML and ALL patients. We found significant differences in serum IL-4, IL-2, IL-3, VEGF and VCAM-1.

We recently published our first experience with biochip arrays for cytokines and adhesion molecules in patients treated for AML. To our knowledge, this is the first published study using the innovative biochip array technology to compare circulating levels of these molecules in newly diagnosed AML and ALL cases.

\section{CONCLUSION}

We conclude that evaluation of serum cytokine and adhesion molecule profile in newly diagnosed acute leukemias can reflect important clinical characteristics. Thus, further studies are needed to establish if the alterations observed in the levels of these molecules could be used as a clinically relevant biomarker for acute leukemias.

Table 1. Serum levels of selected cytokines and adhesion molecules in patients with newly diagnosed acute myeloid leukemia (AML) and acute lymphoblastic leukemia (ALL).

\begin{tabular}{lcrc}
\hline Cytokines and adhesion molecules & AML & ALL & $P$ \\
\hline Interleukin-4 (IL-4) [ng/L] & $4.71 \pm 2.69$ & $1.10 \pm 1.08$ & $<0.0001$ \\
Interleukin-2 (IL-2) [ng/L] & $10.69 \pm 8.55$ & $4.03 \pm 2.15$ & $<0.01$ \\
Interleukin-3 (IL-3) [ng/L] & $18.84 \pm 21.63$ & $7.34 \pm 3.41$ & $<0.05$ \\
Vascular Endothelial Growth Factor (VEGF) [mcg/L] & $63.93 \pm 67.85$ & $139.33 \pm 133.47$ & $<0.05$ \\
Vascular Cell Adhesion Molecule-1 (VCAM-1) [mcg/L] & $716.22 \pm 364.38$ & $1078.54 \pm 456.96$ & $<0.05$ \\
\hline
\end{tabular}




\section{ABBREVIATIONS}

ALL, Acute lymphoblastic leukemia; AML, Acute myeloid leukemia; EGF, Epidermal growth factor; ICAM-1, Intercellular adhesion molecule-1; IFN-gamma, Interferon-gamma; IL, Interleukin; MCP-1, Monocyte chemotactic protein-1; TNF-alpha, Tumor necrosis factor-alpha; VCAM-1, Vascular cell adhesion molecule-1; VEGF, Vascular endothelial growth factor.

\section{ACKNOWLEDGEMENT}

The work was supported by a long-term organization development plan 1011 (Faculty of Military Health Sciences, Hradec Kralove) and by a specific research project "Analysis of defined prognostic factors in acute leukemias" (Faculty of Military Health Sciences, Hradec Kralove).

Author contributions: JMH: manuscript writing, literature search, study design, clinical trial management (data collection, analysis and interpretation); TK: data collection, statistical analysis; MV: laboratory procedures (data analysis); LJ: literature search; PZ: data interpretation, manuscript writing; all authors: final revision.

Conflict of interest statement: None declared.

\section{REFERENCES}

1. Dranoff G. Cytokines in cancer pathogenesis and cancer therapy Nat Rev Cancer 2004;4(1):11-22.

2. Bruserud $\varnothing$, Kittang $A O$. The chemokine system in experimental and clinical hematology. Curr Top Microbiol Immunol 2010;341:3-12.

3. Charalabopoulos K, Binolis J, Karkabounas S. Adhesion molecules in cancerogenesis. Exp Oncol 2002;24(4):249-57.

4. Kupsa T, Horacek JM, Jebavy L. The role of cytokines in acute myeloid leukemia: a systematic review. Biomed Pap Med Fac Univ Palacky Olomouc Czech Repub 2012;156(4):291-301.

5. Leblebisatan G, Antmen B, Saşmaz I, Kilinç Y. Vascular endothelial growth factor levels in childhood acute lymphoblastic and myeloblastic leukemia. Indian J Hematol Blood Transfus 2012;28(1):24-8.

6. Löwenberg B, Touw IP. Hematopoietic growth factors and their receptors in acute leukemia. Blood 1993;81(2):281-92.

7. Konopleva MY, Jordan CT. Leukemia stem cells and microenvironment: biology and therapeutic targeting. Clin Oncol 2011;29(5):591 9.

8. Reikvam H, Hatfield KJ, Fredly H, Nepstad I, Mosevoll KA, Bruserud $\varnothing$. The angioregulatory cytokine network in human acute myeloid leukemia - from leukemogenesis via remission induction to stem cell transplantation. Eur Cytokine Netw 2012;23(4):140-53.
9. Montesinos JJ, Sánchez-Valle E, Flores-Figueroa E, MartínezJaramillo G, Flores-Guzmán P, Miranda-Peralta E, Gutiérrez-Romero $M$, Mayani $H$. Deficient proliferation and expansion in vitro of two bone marrow cell populations from patients with acute myeloid leukemia in response to hematopoietic cytokines. Leuk Lymphoma 2006:47(7):1379-86.

10. Tsimberidou AM, Estey E, Wen S, Pierce S, Kantarjian H, Albitar M, Kurzrock R. The prognostic significance of cytokine levels in newly diagnosed acute myeloid leukemia and high-risk myelodysplastic syndromes. Cancer 2008;113(7):1605-13.

11. Kornblau SM, McCue D, Singh N, Chen W, Estrov Z, Coombes KR. Recurrent expression signatures of cytokines and chemokines are present and are independently prognostic in acute myelogenous leukemia and myelodysplasia. Blood 2010;116(20):4251-61.

12. Sanchez-Correa B, Bergua JM, Campos C, Gayoso I, Arcos MJ, Bañas H, Morgado S, Casado JG, Solana R, Tarazona R. Cytokine profiles in acute myeloid leukemia patients at diagnosis: Survival is inversely correlated with IL-6 and directly correlated with IL-10 levels. Cytokine 2013;61(3):885-91.

13. Reikvam H, Fredly H, Kittang AO, Bruserud $\varnothing$. The possible diagnostic and prognostic use of systemic chemokine profiles in clinical medicine - the experience in acute myeloid leukemia from disease development and diagnosis via conventional chemotherapy to allogeneic stem cell transplantation. Toxins (Basel) 2013;5(2):336-62.

14. Fung FY, Li M, Breunis $\mathrm{H}$, Timilshina $\mathrm{N}$, Minden MD, Alibhai SM Correlation between cytokine levels and changes in fatigue and quality of life in patients with acute myeloid leukemia. Leuk Res 2013;37(3):274-9.

15. Seidel M, Niessner R. Automated analytical microarrays: a critical review. Anal Bioanal Chem 2008;391(5):1521-44.

16. Kricka LJ, Master SR, Joos TO, Fortina P. Current perspectives in protein array technology. Ann Clin Biochem 2006;43(Pt 6):457-67.

17. Fitzgerald SP, McConnell RI, Huxley A. Simultaneous analysis of circulating human cytokines using a high-sensitivity cytokine biochip array. J Proteome Res 2008;7(1):450-5.

18. McAleer D, McPhillips FM, FitzGerald SP, McConnell RI, Rodriguez ML. Application of Evidence Investigator for the simultaneous measurement of soluble adhesion molecules: L-, P-, E-selectins, VCAM-1 and ICAM-1 in a biochip platform. J Immunoassay Immunochem 2006;27(4):363-78.

19. Berrahmoune H, Lamont J, Fitzgerald P, Visvikis-Siest S. Interindividual variation of inflammatory markers of cardiovascular risks and diseases. Clin Chem Lab Med 2005;43(7):671-84.

20. Mehra VC, Ramgolam VS, Bender JR. Cytokines and cardiovascular disease. J Leukoc Biol 2005;78(4):805-18.

21. Kavsak PA, Lee A, Hirte H, Young E, Gauldie J. Cytokine elevations in acute coronary syndrome and ovarian cancer: a mechanism for the up-regulation of the acute phase proteins in these different disease etiologies. Clin Biochem 2008;41(7-8):607-10.

22. Coussens LM, Werb Z. Inflammation and cancer. Nature 2002;420(6917):860-7.

23. Deeg HJ. Cytokines in graft-versus-host disease and the graft-versusleukemia reaction. Int J Hematol 2001;74(1):26-32.

24. Mellgren K, Hedegaard CJ, Schmiegelow K, Müller K. Plasma cytokine profiles at diagnosis in pediatric patients with non-hodgkin lymphoma. J Pediatr Hematol Oncol 2012;34(4):271-5. 